\title{
Studies on lipid profile levels in hypertensive and type 2 diabetes mellitus
}

\author{
Ajuru, Gospel ${ }^{1, ~}$, Okolonkwo, Benjamin², Okeke, Chukwubike ${ }^{3}$ \\ ${ }^{1}$ Department of Anatomical Pathology, Faculty of Basic Medical Science, University of Port Harcourt, Choba, Nigeria \\ ${ }^{2}$ Department of Medical Laboratory Science, Faculty of Science, Rivers State University of Science and Technology, Port Harcourt, \\ Nigeria \\ ${ }^{3}$ Department of Prosthesis and Orthopedic Technology, Federal University of Technology, Owerri, Nigeria
}

Email address:

mexgos_7@yahoo.com (Ajuru, G.), benbruceph@yahoo.com (Okolonkwo, B.),jmdsph@yahoo.com (Okeke, C.)

\section{To cite this article:}

Ajuru, Gospel, Okolonkwo, Benjamin, Okeke, Chukwubike. Studies on Lipid Profile Levels in Hypertensive and Type 2 Diabetes Mellitus. American Journal of Biomedical and Life Sciences. Vol. 2, No. 1, 2014, pp. 28-33. doi: 10.11648/j.ajbls.20140201.15

\begin{abstract}
Studies on the effect of non-hypertensive and hypertensive type 2 diabetes on lipid profile was performed to determine whether these biochemical parameters were affected in individuals associated with these disease conditions. A total of one hundred and thirty-three (133) individuals were used for these studies. Of these thirty-five (35) were established hypertensive diabetics and thirty (30) are established non-hypertensive diabetics. The established hypertensive non-diabetics were thirty-three (33) while thirty-five (35) were normal healthy individuals. The results showed that there was no significant differences $(P>0.05)$ in the mean concentrations of cholesterol, triglycerides, HDL-cholesterol, LDLcholesterol and glucose between hypertensive diabetics and non-hypertensive diabetics studied. The study also showed that there were no significance differences $(P>0.05)$ in the mean levels of all the parameters measured between hypertensive diabetics and hypertensive non-diabetics subjects studied, except for serum glucose that significantly higher $(P<0.05)$ in hypertensive diabetics. It was observed that mean concentrations of cholesterol, triglycerides, LDC-cholesterol, as well as systolic blood pressure were significantly higher $(P<0.05)$ in hypertensive diabetics compared with normal healthy individuals. The results also show that the mean HDL-cholesterol level was significantly lower $(P>0.05)$ in hypertensive diabetics compared with normal healthy individuals. It was also observed that the concentrations of cholesterol, triglycerides, LDL-cholesterol systolic and diastolic blood pressure were significantly higher $(P>0.05)$ in hypertensive non diabetics individuals compared with normal healthy individuals studied. However, the glucose and pulse rate mean levels showed no significant difference $(P>0.05)$ between hypertensive non-diabetics and normal healthy individuals.
\end{abstract}

Keywords: Hypertension, Type 2 Diabetics

\section{Introduction}

Cardiovascular diseases are diseases pertaining to the heart. The term is used to describe the effect of a reduction, interruption or cessation of blood supply to the heart muscle. It may lead to one or the following syndromes. Myocardial, infarction, lingina pectoris, intermitted claudication; stroke, etc. Of all cardiovascular disease, atherosclerosis is the main cause of myocardial infarction and the principal cause of death [1].

Cardiovascular diseases have been the major health problems and the leading cause of death in the United State for decades. Risk factors for the development of cardiovascular disease may be categorized either by relative significance or modifiability [2]. Current guideline jointly accepted by the American Heart Association and the American College cardiology are divided into two groups listed below [2].

Major independent risk factors, cigarette smoking, elevated blood pressure, elevated serum total (LDL) cholesterol, low serum HDL- cholesterol, diabetes mellitus, advancing age. The quantitative relationship between these risk factors and coronary heart disease risk has been elucidated by the Framingham Heart Study [3]; and other studied, which showed that the major risk factors are addictive in predictive power.

Coronary heart disease has been recently recognized as a major problem in women. In fact, it is the primary causes of death in women, exceeding by far the rate of death from malignancies the second leading cause of death for women 
[4]. Diabetes has been shown to be significant risk factors in coronary heart disease. Although the rates for some important risk factors, such as cigarette smoking, elevated cholesterol levels and hypertension, appear to be dealing in the United States, the prevalence of type 2 diabetics, the most common form of diabetes is steadily increasing. In addition, in most ethnic groups, the rates for type 2 diabetics are higher in women than in men [5].

The main class of lipoprotein that causes hypertension and other cardiovascular diseases is low identity lipoprotein (LDL), because it is responsible for the transportation of $75 \%$ of the blood cholesterol to the body cells. It is normally harmless. However, if it is exposed to a process called oxidation, it can penetrate and interact dangerously with the walls of the artery producing a harmless inflammatory response. It has been reported that cholesterol is one of the major risk factor that include the livelihood of developing cardiovascular disease [6]. The disorder of cholesterol such as hypercholesterolemia is predisposing factors to atherosclerosis, ischemic heart disease and stroke.

However, the two component of total serum cholesterol are identified as low density lipoprotein (LDL) cholesterol and high density lipoprotein (HDL) cholesterol [7]. It has been shown that the high density lipoprotein (HDL) and low density lipoprotein (LDL) value can be used in predicting heart attack. Risk factors, such as smoking and lack of exercise also influence the risk of developing heart attack [8].

Diabetes mellitus (DM) and cholesterol levels have generated a lot of interest in recent times, especially people within the ages of 35-60 years. The interest is largely due to the increased level of general awareness on the need for a healthy diet, irrespective of age, sex or socio-economic status and also because of the risk of atherosclerosis, cardiovascular disease, and myocardial infarction [9].

Lipoproteins are biochemical complex generating both proteins and lipids. These lipoproteins are vehicles of lipids transport, carrying lipids (which are non-polar) through the aqueous body fluids. The lipids contained within the core of the lipoproteins are principally either triglycerides or cholesterol. It has been reported that atherosclerosis is a major cause of coronary heart disease (CHD) [10].

Several forms of elevated lipoproteins are inherited. One of more common forms of hyper-lipoprotein is called Type II B, and it's characterized by increased LDL ad VLDL.

Type II B hyperlipoproteinaemia, result in premature handing of the arteries, obstruction of the carotid artery (the artery which supplies blood to the head and brain) peripheral artery disease, heart attack and stroke.

Studies have found a significant connection between hyperlipoproteinaemia in new born and in patients who have suffered heart attack.

Cholesterol belongs to the group of lipids called steroid with a molecular formula $\mathrm{C}_{27} \mathrm{H}_{45} \mathrm{OH}$. Steroids are complex fat soluble molecule, this most abundant of these are the sterols, which are steroid alcohol, and cholesterol is a major sterol in animal tissues. It is solid at room temperature and possesses a cyclopentanoperhydrophenanthrene ring. Several measures have been found to control cholesterol hence, preventing the incidence of cardiovascular disease. They include disease, diet, change of life-style, and increase HDLcholesterol and drugs [11].

Reduce intake of diets rich in cholesterol and saturated fatty acids such as meat, egg, butter, etc. and include intake of food containing polyunsaturated fatty acids such as soya beans oil, corn, olive oil, etc; have been found to reduce hypercholesterolemia hence, prevent the incidences of cardiovascular disease. It has been reported by [12] that decreased intake of diet containing saturated fatty acid and increased consumption of fibres and carbohydrate could reduce blood cholesterol.

\section{Materials and Methods}

The materials used for this study were reagents (kits) for estimation of total cholesterol, high density lipoproteins cholesterol, triglyceride and blood glucose obtained from Randox Laboratories Limited, United Kingdom (UK), and Fluoride oxalate anticoagulants.

\subsection{Methods/Procedures}

A total of one hundred and thirty-three (133) individuals were used for this study. Thirty-five (35) individuals are known to be established hypertensive diabetics while thirty (30) are known to be established non-hypertensive diabetics. Thirty-five (35) are normal healthy individuals who are non-hypertensive and non-diabetics. The subjects were patients recruited from University of Port Harcourt Teaching Hospital, Port Harcourt, Rivers State and Military Hospital, Port Harcourt, Rivers State, Nigeria. The normal healthy individuals were volunteered staff of University of Port Harcourt, Port Harcourt, Rivers State and Rivers State college of Health Sciences, Port Harcourt respectively. After an overnight fasting blood samples (5ml) was obtained from all subjects. Blood samples were processed within two to three hours. Bloods for lipids profile was collected in a plain specimen bottle without anticoagulants, left to clot, spun at $1500 \mathrm{rpm}$ for 10 minutes and serum separated and stored at $4^{0} \mathrm{C}$ until assayed. The serum samples obtained were analyzed for total cholesterol, triglyceride, high density lipoproteins (HDL - cholesterol), low density lipoprotein (LDL - cholesterol) and blood for glucose estimation was collected into a specimen bottle containing fluoride oxalate as anticoagulant.

\subsection{Study Duration}

This study was carried out from June, 2011 to July, 2013

\subsection{Physical Measurements}

The physical parameters such as blood pressure, height and weight were measured from the individuals prior to 
blood collection.

Height was measured without shoes to the nearest $\mathrm{cm}$ using a ruler attached to the wall.

Weight was measured to the nearest $0.1 \mathrm{~kg}$ on an electronic scale weighing balance. The body mass index was calculated as:

$$
\frac{\text { Weight }(\mathrm{kg})}{\text { Square of the height }\left(\mathrm{m}^{2}\right)}
$$

The blood pressure (systolic and diastolic) of the subjects was taken using a calibrated mercury sphygmomanometer by a qualified Nurse. The subject was allowed to sit and relax for about 10 minutes before measurement was performed.

Blood pressure was measured in the left arm using cuffs of a size appropriate to the arm circumference. Also, the pause rate of the subjects was determined.

\subsection{Questionnaire}

A questionnaire was administered which include Name, Place, and Country, Ethnic Groups, Languages, Religion, Occupation, Blood Pressure, Pulse Rate, Family and Personal Medical History, Drug treatment were recorded.

\subsection{Principles and Procedures of Methods}

The principles and procedures of the methods used for the assay of the parameters determined are presented as follows:

\subsubsection{Determination of Total Cholesterol}

Cholesterol was determined by enzymatic colorimetric method [13].

\subsubsection{Principles}

The cholesterol was determined after enzymatic hydrolysis and oxidation. The indicator quinomeimine is formed from hydrogen peroxide and 4 - aminophnazone in the presence of phenol and peroxidase.

The colour intensity determined at $546 \mathrm{~nm}$ is proportional to cholesterol concentration.

$$
\begin{aligned}
& \text { Cholesterol ester }+\mathrm{H}_{2} \mathrm{O} \stackrel{\text { cholesterol }}{\text { Esterase }} \text { Cholesterol }+ \text { fatty acids } \\
& \text { Cholesterol }+0 \stackrel{\text { Cholesterol }}{\longrightarrow} \text { Chidase } \\
& 2 \mathrm{H}_{2} \mathrm{O}_{2}+4-\text { aminophenazone }+ \text { Phenol } \stackrel{\text { peroxidase }}{\longrightarrow} \text { quinoneimine }+4 \mathrm{H}_{2} 0
\end{aligned}
$$

\subsubsection{Procedure}

In glass test tubes pre-labeled reagent blank, standard and test (controls and patient samples), $10 \mu \mathrm{L}$ of distilled water, standard and tests were pipetted into the tubes respectively. This was followed by the addition of $1000 \mu \mathrm{L}$ of reagent into all the tubes. The contents of the tubes were mixed and incubated for 10 minutes at 20 to $25^{\circ} \mathrm{C}$. The absorbance of the standard and test are measured against the reagent blank at $546 \mathrm{~nm}$.

CALCULATION using a standard

$$
\text { Concentration of Cholesterol in the test }=\text { Absorbance of Tests } \quad x \quad \begin{gathered}
\text { Concentration of standard } \\
\text { Absorbance of standard }
\end{gathered}
$$

Result expressed in $\mathrm{Mmol} / \mathrm{L}$

\subsection{Triglyceride}

\subsubsection{Principle}

The triglyceride is determined after enzymatic hydrolysis with lipases. The indicator is a quinoneimine formed from hydrogen 4 aminophenazone and 4 chlorophenol under the catalytic influence of peroxidase.

Triglyceride $+\mathrm{H}_{2} \mathrm{O}$ Lipases glycerol + fatty acids

$$
\begin{aligned}
& \text { Glycerol }+ \text { ATP } \underset{\text { Kinase }}{\stackrel{\text { Glycerol }}{\longrightarrow} \text { glycerol-3- phosphate }+ \text { ADP }} \\
& \text { Glycerol-3-phosphate }+\mathrm{O}_{2} \stackrel{\text { Glycerol phosphate }}{\longrightarrow} \text { Oxidase } \\
& 2 \mathrm{H}_{2} \mathrm{O}_{2}+4 \text { - aminophenazone }+ \text { 4-chlorophenol } \stackrel{\text { Peroxidase }}{\longrightarrow} \text { quinoneimine }+\mathrm{HCL}+4 \mathrm{H}_{2} \mathrm{O}
\end{aligned}
$$

\subsubsection{Procedure}

Into pre-labeled test tubes, $10 \mu \mathrm{L}$ of distilled water, standard test (controls and patients samples) were pipetted respectively, following by $1000 \mu \mathrm{L}$ of reagent to all the tubes. Mixed and incubated for 0 minutes at 20 to $25^{\circ} \mathrm{C}$. The absorbance's of standard and tests were measured against reagent blank at $546 \mathrm{~nm}$.

Calculation using standard

$$
\text { Triglyceride concentration }=\frac{\text { Absorbance of Test }}{\text { Absorbance of standard }} \quad x \quad \begin{gathered}
\text { Concentration of standard } \\
(2.2 \mathrm{Mmol} / \mathrm{L})
\end{gathered}
$$

Result expressed in Mmol/L.

\subsection{High Density Lipoprotein (Hdl - C)}

\subsubsection{Principle}

Low density lipoproteins (LDL and VLDL) and chylomicron fractions are precipitated quantitatively by the addition of phosphotungstic and in the presence of magnesium ions. After centrifugation, the cholesterol concentration in the high density lipoproteir fraction which remains in the supernatant is determined.

\subsubsection{Procedure}

Into pre - labeled glass test tubes, $200 \mu \mathrm{L}$ of standard and tests (control and patient samples) were pipette; Followed by $500 \mu \mathrm{L}$ of diluted precipitant. The tubes were mixed and allowed to sit for 10 minutes at room temperature. They were contrifuged at high speed and the supernatant separated. Into another set of test tubes, labeled reagent blank, standard and tests (controls and patient sample), $100 \mu \mathrm{L}$ of distilled water, standard and tests supernatants were pipetted respectively followed by the addition of $1000 \mu \mathrm{L}$ of reagent, mixed and incubated for 10 minutes at 20 to $250 \mathrm{C}$. The absorbance of standard and tests measured against the reagent blank at 546nm. 
Calculation using standard

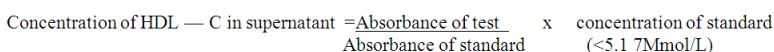

Result expressed in $\mathrm{Mmol} / \mathrm{L}$

\subsection{Low Density Lipoprotein ( $\mathrm{Ldl}-\mathrm{C})$}

LDL - Cholesterol $=$ Total cholesterol - Triglyceride $-\mathrm{HDL}-\mathrm{C}$ 2.2

Result expressed in $\mathrm{MmoL} / \mathrm{L}$

\subsection{Determination of Blood Glucose}

The blood glucose was determined by enzymatic colorimetric method

The enzyme glucose oxidase catalyzes the oxidation of glucose to produce hydrogen peroxide and gluconic acid. In the presence of hydrogen peroxidase, the hydrogen peroxide is broken down and the oxygen released reacts with 4- aninophenazone and phenol to form quinonamine. The absorbance is measured at $340 \mathrm{~nm}$. The color intensity determined by absorbance is proportional to the glucose concentration.

$$
\text { Glucose }+\mathrm{O}_{2}+\mathrm{H}_{2} \mathrm{O} \underset{\text { oxidase }}{\stackrel{\text { Glucose }}{\longrightarrow}} \text { Gluconic acid }+\mathrm{H}_{2} \mathrm{O}
$$

\subsubsection{Procedure}

Into suitable labeled centrifuge tubes, mix well and centrifuge at $2500 \mathrm{rpm}$ for 5 minutes, transfer $1.0 \mathrm{ml}$ supernatant to another test-tube and add $3.0 \mathrm{ml}$ colour reagent. Use $1.0 \mathrm{ml}$ protein precipitant and $3.0 \mathrm{ml}(\mathrm{ml}$ colour reagent for the blank. Mix well and incubate all tubes at $37^{\circ} \mathrm{C}$ for 10 minutes, shaking occasionally to ensure adequate aeration, remove from water bath, cool and measure the absorbance against the blank at $515 \mathrm{~nm}$ (green filter) in $1 \mathrm{~cm}$ cell.

Calculation:

Glucose concentration $(\mathrm{Mmol} / \mathrm{I})=\quad$ A standard $\frac{\text { A sample }}{\mathrm{x} \text { standard concentration }}$

Where A sample change in absorbance of sample

A standard = change in absorbance of sample

\section{Results}

A summary of the results of the parameters measured in hypertensive diabetic subjects and those of nonhypertensive diabetic are shown in table 1. The results show that the mean levels of systolic blood pressure were significantly higher $(P<0.05)$ in established hypertensive diabetes compared to non-Hypertensive diabetes.

There was no significant differences $(P>0.05)$ in the mean concentration of cholesterol, triglycerides, HDLcholesterol diabetic and non-hypertensive diabetic individuals studied. Also no significant differences were observed in the diastolic blood pressure and pulse rate.
The results of the mean value of the biochemical and physical parameters measured in hypertensive diabetic's subjects and those of hypertensive non-diabetes studied are shown in table 2. The result show that there were no significant different $(P>0.05)$ in the mean levels of all the parameter measured between hypertensive diabetic and non-diabetic hypertensive subjects studied; except for glucose, which significantly increased $(P<0.05)$ in hypertensive diabetic patients.

Table 3 show the results of the mean value of the biochemical and physical parameters measured between hypertensive diabetic's individual and normal healthy individuals (non-hypertensive non-diabetics). The results of the study shows that the mean values of cholesterols, triglycerides, LDL-cholesterol, as well as systolic blood pressure were significantly higher $(P<0.05)$ in hypertensive diabetics compared with normal healthy individual. The results also show that the mean concentration of HDLcholesterol was significantly higher $(P<0.05)$ in hypertensive diabetics compared with the normal healthy individuals studied. However, there was no significant different $(P>0.05)$ in the mean levels of their pulse rate and diastolic blood pressure.

The results of the parameters measured for established hypertensive non diabetics, and normal healthy subject are shown in table 4 . The results shown that the mean levels of cholesterol, triglycerides, LDL- cholesterol as well as systolic and diastolic blood pressure were significantly higher $(P<0.05)$ in hypertensive non-diabetic individuals compared with those of normal healthy individuals studied. However, the glucose and pulse rate mean level show no significant difference $(\mathrm{P}>0.05)$ between hypertensive non diabetics and normal healthy individuals.

Table 1. Results of the mean $\pm S D$ of the parameter measured in individuals with established hypertensive diabetics and those of nonhypertensive diabetics.

\begin{tabular}{|c|c|c|c|}
\hline Parameters & $\begin{array}{c}\text { Hypertensive } \\
\text { diabetics } \\
n=35\end{array}$ & $\begin{array}{c}\text { Non- } \\
\text { hypertensive } \\
\text { diabetics } \\
\mathbf{n = 3 0}\end{array}$ & $P$-value \\
\hline Age (years) & $56.91+5.23$ & $54.94+7.87$ & $>.05$ \\
\hline $\begin{array}{l}\text { Systolic B.P } \\
(\mathrm{mmHg})\end{array}$ & $156.33+14.67$ & $129.76+20.45$ & $>.05$ \\
\hline $\begin{array}{l}\text { Diastolic B.P } \\
\quad(\mathrm{mmHg})\end{array}$ & $75.43 \pm 8.57$ & $71 \pm 3.69$ & $>.05$ \\
\hline Height (M) & $1.59 \pm 0.47$ & $1.62 \pm 0.26$ & $>.05$ \\
\hline WGT (Kg) & $72.53+11.28$ & $71.82+12.57$ & $>.05$ \\
\hline Pulse Rate & $77.71+8.27$ & $78.64 \pm 7.50$ & $>.05$ \\
\hline $\begin{array}{l}\text { Body mass index } \\
\qquad\left(\mathrm{Kg} / \mathrm{M}^{2}\right)\end{array}$ & $29.14+4.76$ & $28.27 \pm 3.62$ & $>.05$ \\
\hline CHOL (Mmol/L) & $6.62+1.56$ & $5.89+1.89$ & $<.05$ \\
\hline TG(Mmol/L) & $2.77 \pm 0.87$ & $2.76 \pm 1.02$ & $<.05$ \\
\hline HDL-C (Mmol/L) & $1.52 \pm 0.56$ & $1.50 \pm 0.67$ & $<.05$ \\
\hline LDL-C (Mmol/L) & $3.52+1.98$ & $3.54+2.07$ & $<.05$ \\
\hline Glu Mmol/L & $\begin{array}{l}7.66+1.09 \\
* \text { Mean } \pm \text { SD }\end{array}$ & $7.71 \pm 1.37$ & $<.05$ \\
\hline
\end{tabular}


Tables 2. Results of the mean $+S D$ of the parameters measured in individuals with established hypertensive diabetics and non-diabetics hypertensive.

\begin{tabular}{cccc}
\hline Parameters & $\begin{array}{c}\text { Hypertensive } \\
\text { diabetics } \\
\mathbf{n = 3 5}\end{array}$ & $\begin{array}{c}\text { Non-diabetics } \\
\text { hypertensive } \\
\mathbf{n = 3 5}\end{array}$ & $\boldsymbol{P}$-value \\
\hline Age (years) & $56.91 \pm 5.23$ & $59.56 \pm 4.67$ & $>.05$ \\
Systolic B.P & $156.33 \pm 14.67$ & $155.70 \pm 10.92$ & $>.05$ \\
Diastolic B.P & $75.43 \pm 8.57$ & $85 \pm 7.82$ & $>.05$ \\
Height $(\mathrm{M})$ & $1.59 \pm 0.47$ & $1.55 \pm 0.62$ & $>.05$ \\
WGT $(\mathrm{Kg})$ & $72.53 \pm 11.28$ & $70.17 \pm 1.87$ & $>.05$ \\
Pulse Rate & $77.71 \pm 8.27$ & $80.93 \pm 2.45$ & $>.05$ \\
Body mass index & $29.14 \pm 4.76$ & $29.72 \pm 2.45$ & $>.05$ \\
(Kg/m $\left.{ }^{2}\right)$ & $6.62 \pm 1.56$ & $6.36 \pm 3.05$ & $>.05$ \\
CHOL $(\mathrm{Mmol} / \mathrm{L})$ & $2.77 \pm 0.87$ & $2.47 \pm 1.29$ & $>.05$ \\
TG(Mmol/L) & $1.52 \pm 0.56$ & $1.58 \pm 0.60$ & $>.05$ \\
HDL-C $(\mathrm{Mmol} / \mathrm{L})$ & $3.52 \pm 1.98$ & $3.41 \pm 1.07$ & $>.05$ \\
LDL-C $(\mathrm{Mmol} / \mathrm{L})$ & $7.66 \pm 1.09$ & $4.72 \pm 0.62$ & $>.05$ \\
Glu Mmol/L & $* \mathrm{Mean} \pm \mathrm{SD}$ & & \\
\hline
\end{tabular}

Table 3. Result of the mean $\pm S D$ of the parameters measured in individuals with established hypertensive diabetics and control (normal).

\begin{tabular}{|c|c|c|c|}
\hline Parameters & $\begin{array}{l}\text { Hypertensive } \\
\text { diabetics } \\
\mathrm{n}=35\end{array}$ & $\begin{array}{l}\text { Normal } \\
n=35\end{array}$ & $P$-value \\
\hline Age (years) & $56.91+5.23$ & $50.58+15.94$ & $>.05$ \\
\hline Systolic B.P & $156.33+14.67$ & $113.31+20.34$ & $>.05$ \\
\hline Diastolic B.P & $75.43+8.57$ & $70+5.23$ & $>.05$ \\
\hline Height (m) & $1.59 \pm 0.47$ & $1 . \overline{63}+0.39$ & $>.05$ \\
\hline WGT. (kg) & $72.53+11.28$ & $73.27 \pm 1.32$ & $>.05$ \\
\hline Pulse rate & $77.71 \pm 8.27$ & $76.17 \pm 1.72$ & $>.05$ \\
\hline $\begin{array}{l}\text { Body mass index } \\
\left(\mathrm{kg} / \mathrm{m}^{2}\right)\end{array}$ & $29.14+4.76$ & $28.73 \pm 3.09$ & $>0.05$ \\
\hline CHOL (Mmol/L) & $6.62 \pm 1.56$ & $4.01+2.46$ & $<.05$ \\
\hline $\mathrm{TG}(\mathrm{Mmol} / \mathrm{L})$ & $2.77 \pm 0.87$ & $1.54+1.08$ & $<.05$ \\
\hline $\begin{array}{l}\text { HDL-C } \\
(\mathrm{Mmol} / \mathrm{L})\end{array}$ & $1.52 \pm 0.56$ & $2.06 \pm 0.75$ & $<.05$ \\
\hline $\begin{array}{l}\text { LDL-C } \\
(\mathrm{Mmol} / \mathrm{L})\end{array}$ & $3.52+1.98$ & $2.25 \pm 0.94$ & $<.05$ \\
\hline Glu $\mathrm{Mmol} / \mathrm{L}$ & $\begin{array}{l}7.66 \pm 1.09 \\
* \text { Mean } \pm \text { SD }\end{array}$ & $4.66 \pm 0.84$ & $<.05$ \\
\hline
\end{tabular}

Table 4. results of the mean $+S D$ of the parameters measured in individuals with established hypertensive, but not diabetics and normal healthy individuals.

\begin{tabular}{cccc}
\hline Parameters & $\begin{array}{c}\text { Hypertensive } \\
\text { non-diabetics } \\
\mathbf{n = 3 3}\end{array}$ & $\begin{array}{c}\text { Normal } \\
\mathbf{n = 3 5}\end{array}$ & $\boldsymbol{P}$-value \\
\hline Age (years) & $59.56 \pm 4.67$ & $50.58 \pm 15.94$ & $>0.05$ \\
Systolic B.P & $155.70 \pm 10.92$ & $113.31 \pm 20.34$ & $>.05$ \\
(mmHg) & $85 \pm 7.82$ & $70 \pm 5.23$ & $<.05$ \\
Diastolic B.P & $1.55 \pm 0.62$ & $1.63 \pm 0.39$ & $>.05$ \\
Height (M) & $70.17 \pm 1.87$ & $73.27 \pm 1.32$ & $>.05$ \\
WGT (Kg) & $80.93 \pm 2.45$ & $76.17 \pm 1.72$ & $>.05$ \\
Pulse Rate & $29.72 \pm 2.45$ & $28.73 \pm 3.09$ & $>.05$ \\
Body mass index & $6.36 \pm 3.05$ & $4.01 \pm 2.46$ & $>.05$ \\
(Kg/m $\left.{ }^{2}\right)$ & $2.47 \pm 1.29$ & $1.54 \pm 1.08$ & $>.05$ \\
CHOL (Mmol/L) & $1.58 \pm 0.60$ & $2.06 \pm 0.75$ & $>.05$ \\
TG(Mmol/L) & $3.41 \pm 1.07$ & $2.25 \pm 0.94$ & $>.05$ \\
HDL-C $(\mathrm{Mmol} / \mathrm{L})$ & $4.72 \pm 0.62$ & $4.66 \pm 0.84$ & $>0.05$ \\
LDL-C $(\mathrm{Mmol} / \mathrm{L})$ & $* \mathrm{Mean} \pm \mathrm{SD}$ & & \\
\hline Glu Mmol/L & &
\end{tabular}

\section{Discussion}

It was observed that values of cholesterol, triglycerides, LDL-C, as well as systolic blood pressure measured were higher in hypertensive diabetics compared with normal healthy individuals.

While also the concentration of HDL-cholesterol level was lower in hypertensive diabetics compared with normal healthy individuals. These observations were consistent with previous reports that hyperlipidaemia is usually present in diabetes mellitus and in hypertension [14]. It also indicates that hyperlipidaemia is a serious risk factor for the development of coronary artery disease.

Furthermore, it is suggested that the however concentration $\mathrm{s}$ of HDL- cholesterol in non-diabetics hypertensive and hypertensive diabetics seems to augments the danger of coronary artery disease in these conditions [15].

The biochemical parameters estimated were observed to show no significant differences between hypertensive diabetic and non diabetic hypertensive studied except for serum glucose concentration that was found to be higher in hypertensive diabetics. However the elevated blood glucose (hyperglycemia) observed is equated with diabetes.

\section{Conclusion}

The significant physical and biochemical effects observed are important in the diagnosis and treatment of this chronic metabolic disease. However, it is particularly challenging since many of the agents used to lower blood pressure can affect glucose metabolism adversely. Further studies shows that glucose intake of diabetic patient should be discourage since this is one of the predisposing factors.

\section{Acknowledgements}

The authors gratefully acknowledge Dr Wankasi of the Department of Medical Laboratory Science, Niger Delta University, Yenagoa, Bayelsa State, Nigeria, for his useful suggestions, advice, and guidance.

\section{References}

[1] Mayne, DP. Plasma Lipids and Lipometenis, in: Clinical Chemistry in Diagnosis and Treatment. Sixth edition, Oxford University Press, Inco. New York; 1996.

[2] Grundy SM, Pasternak R Greenland P. (1999). Assessment of Cardiovascular Risk Factor, Assessment Equation Journal of American glucose of Cardiology. 1999; 34:1248-1359.

[3] Wilson PH, Dagostino RB, Levy D. Prediction of Coronary Heart Disease Using Risk Factor Categories. Circulations. 1998; 97; 1837-1847.

[4] Harlan WR. Cardiovascular Disease Care for Women: Service Utilization, Disability Utilization, and Expenditure Survey. In: Eaker ED, Packard B, Wenaer NK, Clarkson TB, Tyroler HA's Coronary Heart Disease in Women. $4^{\text {th }} \mathrm{Ed}$, New York, Haymanket Doyma; 1986 
[5] Harris MI, Hadden WC, Knowler WC, Bennet PH. Mevalence of Diabetus and Impaired Glucose Tolerance and Plasma Glucose levels in U.S. Population aged 20-74 years Diabetics. 1987; 36:523-523, 534.

[6] Sokolow M, Malwen BM. Coronary Disease In: Clinical Cardiology, $2^{\text {nd }}$ edition, Lans Medical Publications, California; 1979

[7] Tietz NW. Lipid, Apolipopotients. In: Fundamentals of Clinical Chemistry, $6^{\text {th }}$ edition, WB Saunders Company, London; 2003

[8] Alderman MH, Cohen H, Mad Haven S, Kivilann S. Serum Uric acid and Cardiovascular Disease events in Successfully Treated Hypertensive Patient. Hypertensive. 1999; 34:144150 .

[9] Bishop ML, Duben, Engelkiri, JL, Fody, EP. Carbohydrate, Diabetes mellitus. In: Clinical chemistry, Principles, Procedures, Correlations, $2^{\text {nd }}$ edition, J.B. Lippincott company, 1991.
[10] Roberts WC. Preventing and Arresting Coronary Atherosileresis. American heat Journal. 1995; 130:580-597.

[11] Lehninger AL. The biosynthesis of lipids. In: Principles of Biochemistry, $2^{\text {nd }}$ edition, Worth Publishers Inc, New York. 1993

[12] Garcia A, Gutiierrez JM, Fernandez S, Aparicio J, Menendez PA. Dietary Intervention in a Hypercholusterolemic School Aged Population from Northern Spain. Journal of Revolution of Physiology. 1996; 52:49-58.

[13] Trinder P. Diagnosis of Coronary Heart Disease. Annals of Clinical Biochemistry. 1997; 6: 24.

[14] Tilkian MS, Conover BM, Tilkian GA. Clinical Implications of Laboratory Tests; $2^{\text {nd }}$ edition, the C.V. mosby company, London. 1979

[15] Kaplan A, Szabo LL, Opheim, EK. Clinical interpretation and techniques, $3^{\text {rd }}$ edition, Lee and Febiger, Philadelphia. 1988. 